\title{
Modifiable Predictors of Chronotropic Incompetence in Male Patients With Type 2 Diabetes
}

\author{
Dominique Hansen, PhD; Paul Dendale, MD, PhD
}

PURPOSE: Type 2 diabetes mellitus (T2DM) is associated with chronotropic incompetence $(\mathrm{Cl})$, which may lead to a worse prognosis. It remains uncertain whether $\mathrm{Cl}$ in T2DM patients is related to patient characteristics that are modifiable by exercise interventions.

METHODS: From 33 male T2DM patients and 18 healthy subjects not taking $\beta$-blockers, calcium-antagonists, and/or diuretics, a fasting blood sample was collected, followed by an oral glucose tolerance test, maximal cardiopulmonary exercise test, and body composition analysis. Chronotropic incompetence was defined as the inability to achieve a maximal chronotropic response index $(\max C R I) \geq 0.80$ during exercise testing. By univariate correlations and multivariate regression analysis, relationships between exercise tolerance, body composition, glycemic control, and maxCRI were examined.

RESULTS: MaxCRI was significantly lower in T2DM patients $(0.85 \pm 0.17)$ vs healthy controls $(1.02 \pm 0.17, P<.01)$ : Chronotropic incompetence was prevalent in 14 T2DM patients $(42 \%)$ and 1 healthy subject $(6 \%$, $P<$.05). Significant $(P<.05)$ univariate correlations between maxCRI and body mass index $(r=-0.59)$, blood high-density lipoprotein cholesterol $(r=0.34), \mathrm{HbA}_{1 \mathrm{c}}(r=-0.33)$ and insulin level $(r=-0.48)$, HOMA-IR index $(r=-0.45)$, trunk adipose tissue mass $(r=-0.45)$, waist circumference $(r=-0.58)$, peak cycling power output $(r=$ $0.42)$, and oxygen uptake $(r=0.33)$ were found $(P<.05)$. Independent significant relations were found between maxCRI and waist circumference $(P<.01)$ and peak cycling power output $(P<.05)$.

CONCLUSIONS: Chronotropic incompetence in male T2DM patients is independently related to exercise tolerance and adipose tissue mass. These data provide further insight into the etiology of $\mathrm{Cl}$ in male T2DM patients and show that exercise interventions might impact predictors of $\mathrm{Cl}$.

\section{$\begin{array}{llllllll}K & E & Y & W & O & R & D & S\end{array}$}

chronotropic incompetence

exercise testing

type 2 diabetes
Author Affiliations: Biomedical Research Institute, Faculty of Medicine and Life Sciences, Hasselt University, Diepenbeek, Belgium; and Heart Centre Hasselt, Jessa Hospital, Hasselt, Belgium.

Conflicts of interest: None declared.

Correspondence: Dominique Hansen, PhD, Hasselt University, Faculty of Medicine and Life Sciences, Agoralaan, Bldg A, 3590 Diepenbeek, Belgium (Dominique.hansen@ uhasselt.be).

DOI: 10.1097/HCR.0000000000000039
Type 2 diabetes mellitus (T2DM) is often associated with chronotropic incompetence (CI), ${ }^{1}$ which is defined as the inability of the heart rate (HR) to increase commensurate with increased physical activity or metabolic demand. ${ }^{2}$ Chronotropic incompetence in T2DM patients could result from myocardial fibrosis, microvascular ischemia, cardiac autonomic neuropathy, ${ }^{1}$ and/or other currently unknown mechanisms. ${ }^{3,4}$ Previous studies have demonstrated that T2DM patients with CI are at an increased risk for future cardiovascular events. ${ }^{5}$ However, despite the prognostic value and easy assessment of CI during maximal exercise testing, its importance remains underappreciated and is often overlooked in clinical practice. ${ }^{2}$ 
Moreover, it remains to be explored whether subject characteristics, which are modifiable by exercise interventions, are related to CI in T2DM patients. This study investigated which patient characteristics that are associated with CI may be potentially modified by exercise interventions. In this regard, the contribution of exercise tolerance, body composition, and glycemic control to CI remains unclear in T2DM patients. ${ }^{6,7}$ The aim of this study was to examine the contribution of exercise tolerance, body composition, and glycemic control to CI in T2DM patients. The etiology of CI in T2DM was further explored and which subject characteristics should be targeted with exercise interventions when trying to remediate CI.

\section{METHODS}

Nonsmoking white males $(\mathrm{N}=51)$ were selected to participate in this study: 33 T2DM patients and 18 healthy subjects. Patients with T2DM had been diagnosed for at least 12 months prior to investigation, did not have a history of cardiovascular disease, and were all treated with oral blood glucose-lowering medication. Subjects did not participate in any regular exercise and/or caloric intake restriction program for at least 5 years and did not take $\beta$-blockers, calciumantagonists, and/or diuretics. Written informed consent was obtained from the subjects and the study was approved by the local medical ethical committee of Jessa Hospital, Hasselt, Belgium.

\section{Study Design}

All measurements were performed at the same time of day and with the same chronology: fasting blood sample, oral glucose tolerance test (OGTT), and maximal exercise test. A few days later, a dual x-ray absorptiometry scan was executed in the fasting condition.

\section{Medication, Diet, and Physical Activity Prior to Testing}

Three days before testing, subjects stopped taking oral blood glucose and/or lipid-lowering medication. All subjects refrained from any heavy physical exercise/ labor for at least 3 days before testing. The evening prior to the test, all subjects received the same standardized meal.

\section{Blood Analysis}

Subjects reported at the laboratory after an overnight fast. After 20 minutes of rest, a venous blood sample was collected. Then a 2-hour OGTT (with 75-g oral glucose load) was performed with blood sample collections done every 30 minutes. Blood samples were analyzed in the hospital clinical laboratory for glucose, glycosylated hemoglobin $\left(\mathrm{HbA}_{1 \mathrm{c}}\right)$, insulin, total cholesterol, high-density lipoprotein (HDL) cholesterol, low-density lipoprotein cholesterol, free fatty acid, and triglyceride content. Homeostasis model assessment-estimated insulin resistance (HOMA-IR index) was calculated to estimate whole-body insulin resistance: [insulin $(\mathrm{mu} / \mathrm{L}) \times$ glucose $\left._{(\mathrm{mmol} / \mathrm{L})}\right] / 22.5$. From the serial blood glucose measurements during OGTT, the glucose area under the curve was calculated.

\section{Maximal Exercise Test and Chronotropic Competence Analysis}

Peak oxygen uptake $\left(\mathrm{V}_{2 \text { peak }}\right)$ and cycling power output $\left(\mathrm{W}_{\text {peak }}\right)$ were assessed during a maximal incremental exercise test on a cycle ergometer (Ergo 1500 cycle; Ergofit GmbH, Pirmasens, Germany) using a 3-minute work stage protocol (starting load 45 watts, load increments 45 watts). $\mathrm{VO}_{2}$ was measured continuously (CS 200; Schiller AG, Baar, Switzerland) and HR was monitored continuously using a 12-lead electrocardiogram. Achievement of a peak respiratory gas exchange ratio $\left(\mathrm{RER}_{\text {peak }}\right)>1.10$ was the goal for all patients.

From these exercise test results, chronotropic competence was analyzed. Resting HR was assessed while sitting on bike for 1 minute, from which the lowest recorded $\mathrm{HR}$ was considered as resting $\mathrm{HR}$. Agepredicted maximal HR was calculated using the equation 220-age in years. Maximal chronotropic response index (maxCRI) was calculated using the following equation: (actual peak HR - resting HR) / (predicted peak HR - resting HR). ${ }^{2}$ Chronotropic incompetence was defined as the inability to achieve a maxCRI $\geq$ $0.80 .^{2}$

\section{Body Composition}

Body mass was measured using a calibrated analog weight scale. Adipose tissue mass and fat-free mass were determined using whole-body dual x-ray absorptiometry (Lunar DPXL, WI). ${ }^{8}$ Waist circumference was quantified at the level of noticeable waist narrowing located between costal border and iliac crest. This circumference was assessed 3 times, with the average of the 3 measurements recorded.

\section{Statistical Analysis}

Data were expressed as mean \pm SD. Because data from various parameters were not normally distributed (Shapiro-Wilk tests, $P<.05$ ), nonparametric tests were used. To compare groups, Mann-Whitney $U$ tests and $\chi^{2}$ tests were applied. In addition, the relationships between parameters were analyzed by Spearman correlations. Next, a multiple regression model was constructed to predict chronotropic competence (maxCRI). In this model, an indicator for 
body composition, glycemic control, and exercise tolerance (showing the greatest significant univariate correlations with maxCRI in the total sample), as well as age, was included. Statistical significance was set at $P<.05$. Data analyses were performed using SPSS $\mathrm{V} 18.0$.

\section{RESULTS}

Subject characteristics are summarized in Table 1. Subjects took the following medications: thiazolidinedione $(n=2)$, metformin $(n=24)$, sulfonylurea

\section{Ta b le 1 - Subject Characteristics ${ }^{\mathrm{a}}$}

\section{T2DM Patients}

General features

Age, $y$

Body weight, $\mathrm{kg}$

Height, $\mathrm{m}$

Body mass index, $\mathrm{kg} / \mathrm{m}^{2}$

Blood parameters

Total cholesterol, $\mathrm{mmol} / \mathrm{L}$

$\mathrm{HDL}$ cholesterol, $\mathrm{mmol} / \mathrm{L}$

LDL cholesterol, $\mathrm{mmol} / \mathrm{L}$

Triglycerides, $\mathrm{mmol} / \mathrm{L}$

Free fatty acids, $\mathrm{mmol} / \mathrm{L}$

Fasting glucose, $\mathrm{mmol} / \mathrm{L}$

Glucose at 120-min OGTT, $\mathrm{mmol} / \mathrm{L}$

Fasting insulin, $\mathrm{mU} / \mathrm{L}$

HOMA-IR index

Area under the curve during OGTT, $\mathrm{mmol} / \mathrm{L} \times \min$

Glycosylated hemoglobin, \%

Body composition

Trunk lean tissue mass, $\mathrm{kg}$

Trunk adipose tissue mass, $\mathrm{kg}$

Trunk adipose tissue, $\%$

Legs lean tissue mass, $\mathrm{kg}$

Legs adipose tissue mass, $\mathrm{kg}$

Legs adipose tissue, \%

Waist circumference, $\mathrm{cm}$

Exercise capacity

Peak cycling power output, $\mathrm{W}$

Peak oxygen uptake, $\mathrm{mL} / \mathrm{min}$

Percentage predicted peak oxygen uptake, \%

Peak oxygen uptake, $\mathrm{mL} / \mathrm{min} / \mathrm{kg}$, legs lean tissue mass

Peak expiratory volume, $\mathrm{L} / \mathrm{min}$

Peak respiratory gas exchange ratio

Peak heart rate, bpm

$$
\begin{gathered}
59 \pm 7 \\
89 \pm 11 \\
1.74 \pm 0.06 \\
29.6 \pm 3.4 \\
5.0 \pm 0.7 \\
1.2 \pm 0.2 \\
3.1 \pm 0.7 \\
1.9 \pm 2.1 \\
421 \pm 110 \\
9.1 \pm 2.4 \\
15.3 \pm 5.8 \\
14.8 \pm 6.1 \\
6.0 \pm 3.3 \\
1.69 \pm 0.39 \\
7.0 \pm 0.9
\end{gathered}
$$

$30.3 \pm 2.8$

$17.5 \pm 4.2$

$36.2 \pm 4.8$

$18.8 \pm 2.2$

$5.6 \pm 1.8$

$22.5 \pm 5.1$

$106 \pm 10$

$176 \pm 32$

$2128 \pm 402$

$74 \pm 14$

$115 \pm 24$

$70 \pm 16$

$1.15 \pm 0.05$

$150 \pm 13$
Healthy Subjects

$$
\begin{gathered}
55 \pm 5^{b} \\
80 \pm 8^{b} \\
1.75 \pm 0.05 \\
26.0 \pm 2.0^{b}
\end{gathered}
$$

$$
\begin{aligned}
5.7 & \pm 0.8^{b} \\
1.4 & \pm 0.3^{b} \\
3.7 & \pm 0.8^{b} \\
1.4 & \pm 0.7 \\
332 & \pm 131^{b} \\
5.8 & \pm 0.8^{b} \\
6.4 & \pm 1.7^{b} \\
10.3 & \pm 3.9^{b} \\
2.7 & \pm 1.1^{b} \\
0.91 & \pm 0.18^{b} \\
5.4 & \pm 0.7^{b}
\end{aligned}
$$

$28.0 \pm 2.4^{\mathrm{b}}$

$12.9 \pm 3.4^{\mathrm{b}}$

$31.1 \pm 6.4^{b}$

$18.6 \pm 2.0$

$5.0 \pm 1.6$

$21.0 \pm 4.8$

$93 \pm 7^{b}$

$226 \pm 44^{b}$

$2499 \pm 565^{b}$

$85 \pm 19^{b}$

$134 \pm 27^{b}$

$86 \pm 20^{b}$

$1.19 \pm 0.06^{b}$

$165 \pm 17^{b}$

Abbreviations: HDL, high-density lipoprotein; HOMA-IR, homeostasis model of assessment-insulin resistance; LDL, low-density lipoprotein; OGTT, oral glucose tolerance test; T2DM, type 2 diabetes mellitus; W, watts.

${ }^{\text {aData }}$ are expressed as mean $\pm \mathrm{SD}$.

b $P<.05$. 
$(\mathrm{n}=15)$, alpha-glucosidase inhibitor $(\mathrm{n}=1)$, ezetimibe $(\mathrm{n}=1)$, statin $(\mathrm{n}=19)$, fibrate $(\mathrm{n}=1)$, angiotensinconverting enzyme inhibitor $(\mathrm{n}=8)$, angiotensin receptor blocker $(n=2)$, and antiplatelet $(n=5)$. Average duration of T2DM was $5.2 \pm 4.4$ years.

\section{Chronotropic Competence}

Between healthy subjects and T2DM patients, percent predicted peak HR and maxCRI was significantly higher in healthy subjects (100 $\pm 8 \%$ and $1.02 \pm 0.16$, respectively) as opposed to T2DM patients (93 $\pm 8 \%$ and $0.85 \pm 0.17$, respectively) $(P<.05)$. Chronotropic incompetence was present in 1 healthy subject (6\%) and in 14 T2DM patients $(42 \%, P<.05)$.

\section{Correlations}

In the total sample, correlations between maxCRI and body mass index, blood HDL cholesterol, $\mathrm{HbA}_{1 \mathrm{c}}$ and insulin level, HOMA-IR index, trunk lean and adipose tissue mass, waist circumference, peak cycling power output, and $\mathrm{VO}_{2 \text { peak }}\left(\mathrm{mL} \cdot \mathrm{kg}^{-1} \cdot \mathrm{min}^{-1}\right.$, lean tissue mass legs) were present (Table 2). In addition, independent relationships were found between maxCRI and waist circumference $(P<.01)$ and peak cycling power

\section{Ta ble 2 Correlations With Maximal Chronotropic Response Index}

\begin{tabular}{|c|c|c|c|}
\hline & Total Sample & Healthy Subjects & T2DM Patients \\
\hline Age & -0.07 & -0.45 & 0.26 \\
\hline Body mass index & $-0.59^{\mathrm{a}}$ & -0.09 & $-0.61^{\mathrm{a}}$ \\
\hline T2DM duration & $\cdots$ & $\cdots$ & 0.24 \\
\hline Total cholesterol & 0.19 & 0.02 & -0.05 \\
\hline HDL cholesterol & $0.34^{\mathrm{a}}$ & -0.22 & $0.35^{\mathrm{a}}$ \\
\hline LDL cholesterol & 0.17 & 0.10 & -0.04 \\
\hline Triglycerides & -0.06 & 0.36 & -0.20 \\
\hline Free fatty acids & -0.15 & 0.16 & -0.16 \\
\hline Fasting glucose & -0.19 & 0.39 & 0.07 \\
\hline Glucose at $120-\min$ OGTT & -0.26 & -0.08 & 0.18 \\
\hline Fasting insulin & $-0.48^{\mathrm{a}}$ & 0.09 & $-0.57^{a}$ \\
\hline Fasting HOMA-IR index & $-0.45^{\mathrm{a}}$ & 0.23 & $-0.47^{a}$ \\
\hline AUC OGTT & -0.22 & 0.18 & 0.16 \\
\hline Glycosylated hemoglobin & $-0.33^{\mathrm{a}}$ & -0.06 & -0.01 \\
\hline Trunk lean tissue mass & $-0.29^{\mathrm{a}}$ & -0.03 & -0.21 \\
\hline Trunk adipose tissue mass & $-0.45^{\mathrm{a}}$ & 0.07 & $-0.50^{\mathrm{a}}$ \\
\hline Trunk $\%$ adipose tissue & $-0.39^{\mathrm{a}}$ & 0.21 & $-0.49^{a}$ \\
\hline Legs lean tissue mass & -0.18 & 0.04 & -0.28 \\
\hline Legs adipose tissue mass & -0.19 & 0.41 & $-0.39^{a}$ \\
\hline Legs $\%$ adipose tissue & -0.15 & 0.42 & $-0.35^{\mathrm{a}}$ \\
\hline Waist circumference & $-0.58^{\mathrm{a}}$ & -0.18 & $-0.53^{\mathrm{a}}$ \\
\hline Resting heart rate & 0.18 & $0.76^{\mathrm{a}}$ & -0.10 \\
\hline Peak cycling power output & $0.42^{\mathrm{a}}$ & 0.21 & 0.33 \\
\hline Peak oxygen uptake & 0.23 & 0.21 & 0.09 \\
\hline$\%$ predicted peak oxygen uptake & 0.26 & 0.01 & 0.28 \\
\hline Peak oxygen uptake, legs lean tissue mass & $0.33^{\mathrm{a}}$ & 0.07 & 0.26 \\
\hline
\end{tabular}

Abbreviations: AUC, area under the curve; HDL, high-density lipoprotein; HOMA-IR, homeostasis model of assessment-insulin resistance; LDL, low-density lipoprotein; OGTT, oral glucose tolerance test; T2DM, type 2 diabetes mellitus.

ap $<.05$. 
output $(P<.05)$, but not HOMA-IR index $(P=.22)$ and age $(P=.15)$.

\section{DISCUSSION}

The degree of CI, based on calculation of the maxCRI, was significantly greater in male subjects with T2DM as opposed to healthy subjects. Moreover, maxCRI was independently related to exercise tolerance and adipose tissue mass.

In this study, CI was prevalent in $42 \%$ of $\mathrm{T} 2 \mathrm{DM}$ patients. In populations with heart failure and/or heart rhythm disturbances, the prevalence of CI can vary from $9 \%$ up to $89 \%$, depending on which criteria were handled to establish CI. ${ }^{2}$ In other studies involving patients with T2DM, similar ranges of CI prevalence can be found, ${ }^{1,5-7}$ depending on the criteria to establish CI, but also depending on the severity of autonomic neuropathy. Although an exact prevalence rate of $\mathrm{CI}$ in T2DM remains difficult to determine, it has become clear that CI could be highly prevalent in T2DM patients. Therefore, clinicians could be confronted frequently with this exercise test anomaly when evaluating T2DM patients.

The exact mechanism by which CI leads to elevated cardiovascular events remains speculative. ${ }^{3,4}$ However, in the present study, significant univariate correlations in the total sample between maxCRI and blood HDL cholesterol $(r=0.34)$ and glycosylated hemoglobin $(r=-0.33)$, degree of insulin resistance based on HOMA-IR index $(r=-0.45)$, trunk adipose tissue mass $(r=-0.45)$, and exercise tolerance based on peak cycling power output $(r=0.42)$ were found. It follows that lower blood HDL cholesterol, insulin resistance and/or poor glycemic control, elevated trunk adipose tissue mass, and/or lowered exercise tolerance, which is particularly present in subjects with low maxCRI, could further explain the elevated risk for cardiovascular events.

Our results are consistent with previous studies reporting a correlation between maxCRI and exercise tolerance (based on peak cycling power output, $r=$ $0.42)$, but not blood glucose content $(r=-0.19) .5,7$ It was, however, noticed that maxCRI correlated with the degree of insulin resistance (based on HOMA-IR index, $r=-0.45$ ). Previous studies have also reported correlations between the degree of insulin resistance and left ventricular function ${ }^{10}$ and resting HR. ${ }^{11}$ It is known that hyperinsulinemia, which is present in subjects with insulin resistance, leads to reduced baroreceptor sensitivity. ${ }^{12}$ This reduced baroreceptor sensitivity could lead to reduced maxCRI. ${ }^{13}$

Independent significant relationships were found between maxCRI and exercise tolerance based on peak cycling power output $(P<.05)$ and trunk adipose tissue mass based on waist circumference $(P<.01)$, regardless of age $(P=.15)$ and degree of insulin resistance based on HOMA-IR index $(P=.22)$, thereby explaining $44 \%$ of the variance in maxCRI. A blunted HR increase during exercise testing contributes to a lowered cardiac output, thus leading to reduced exercise tolerance. ${ }^{14}$ This might explain the relation between maxCRI and exercise tolerance. An independent relationship between maxCRI and trunk adipose tissue mass could be explained by the significantly blunted epinephrine release that is observed in subjects with obesity during maximal exercise testing. ${ }^{15}$ This situation would ultimately lead to CI.

In conclusion, the degree of $\mathrm{CI}$ in male T2DM patients is independently related to exercise tolerance and adipose tissue mass. Since these patient characteristics are potentially modifiable by exercise interventions, further research should examine whether modifying these factors as a result of exercise training affects CI in T2DM patients.

\section{-Acknowledgment-}

This study was funded by a research grant from Hartcentrum Hasselt vzw, Belgium.

\section{References}

1. Jellis CL, Stanton T, Leano R, et al. Usefulness of at rest and exercise hemodynamics to detect subclinical myocardial disease in type 2 diabetes mellitus. Am J Cardiol. 2011;107:615-621.

2. Brubaker PH, Kitzman DW. Chronotropic incompetence: causes, consequences, and management. Circulation. 2011;123:1010-1020.

3. Kiviniemi AM, Tulppo MP, Hautala AJ, et al. Long-term outcome of patients with chronotropic incompetence after an acute myocardial infarction. Ann Med. 2011;43:33-39.

4. Savonen KP, Kiviniemi V, Laukkanen JA, et al. Chronotropic incompetence and mortality in middle-aged men with known or suspected coronary heart disease. Eur Heart J. 2008;29:1896-1902.

5. Felsher J, Meissner MD, Hakki AH, et al. Exercise thallium imaging in patients with diabetes mellitus: prognostic implications. Arch Intern Med. 1987;147:313-317.

6. Brassard P, Ferland A, Bogaty P, et al. Influence of glycemic control on pulmonary function and heart rate in response to exercise in subjects with type 2 diabetes mellitus. Metabolism. 2006; $55: 1532-1537$.

7. Khoshdel AR, Carney SL, White S. Disturbed hemodynamic cardiac exercise stress test response in non-smoking, normolipidemic, normotensive, diabetic subjects. Diab Res Clin Pract. 2007;75:193-199.

8. Glickman SG, Marn CS, Supiano MA, et al. Validity and reliability of dual-energy x-ray absorptiometry for the assessment of abdominal adiposity. J Appl Physiol. 2004;97:509-514.

9. Bottini P, Tantucci C, Scionti L, et al. Cardiovascular response to exercise in diabetic patients: influence of autonomic neuropathy of different severity. Diabetologia. 1995;38:244-250.

10. Sasso FC, Carbonara O, Nasti R, et al. Effects of insulin on left ventricular function during dynamic exercise in overweight and obese subjects. Eur Heart J. 2005;26:1205-1212.

11. Facchini FS, Stoohs RA, Reaven GM. Enhanced sympathetic nervous system activity. The linchpin between insulin 
resistance, hyperinsulinemia, and heart rate. Am J Hypertens. 1996;9:1013-1017.

12. Watkins LL, Surwit RS, Grossman P, et al. Is there a glycemic threshold for impaired autonomic control? Diabetes Care. 2000;23:826-830.

13. Fukuma N, Kato K, Munakata K, et al. Baroreflex mechanisms and response to exercise in patients with heart disease. Clin Physiol Funct Imaging. 2012;32:305-309.
14. Samejima H, Omiya K, Uno M, et al. Relationship between impaired chronotropic response, cardiac output during exercise, and exercise tolerance in patients with chronic heart failure. Jpn Heart J. 2003;44:515-525.

15. Salvadori A, Fanari P, Giacomotti E, et al. Kinetics of catecholamines and potassium, and heart rate during exercise testing in obese subjects. Heart rate regulation in obesity during exercise. Eur J Nutr. 2003;42:181-187. 